Research Article

\title{
Heat-Activated Persulfate Oxidation of Chlorinated Solvents in Sandy Soil
}

\author{
Jialu Liu, ${ }^{1}$ Xijun Gong, ${ }^{1}$ Shijun Song, ${ }^{2}$ Fengjun Zhang, ${ }^{1}$ and Cong Lu' \\ ${ }^{1}$ Key Laboratory of Groundwater Resources and Environment, Ministry of Education, Jilin University, Changchun 130021, China \\ ${ }^{2}$ School of Nursing, Jilin University, Changchun 130021, China \\ Correspondence should be addressed to Cong Lu; lvcong@jlu.edu.cn
}

Received 1 July 2014; Accepted 15 July 2014; Published 3 August 2014

Academic Editor: Tifeng Jiao

Copyright (c) 2014 Jialu Liu et al. This is an open access article distributed under the Creative Commons Attribution License, which permits unrestricted use, distribution, and reproduction in any medium, provided the original work is properly cited.

\begin{abstract}
Heat-activated persulfate oxidative treatment of chlorinated organic solvents containing chlorinated ethenes and ethanes in soil was investigated with different persulfate dosages $(20 \mathrm{~g} / \mathrm{L}, 40 \mathrm{~g} / \mathrm{L}$, and $60 \mathrm{~g} / \mathrm{L})$ and different temperatures $\left(30^{\circ} \mathrm{C}, 40^{\circ} \mathrm{C}\right.$, and $\left.50^{\circ} \mathrm{C}\right)$. Chlorinated organic solvents removal was increased as persulfate concentration increase. The persulfate dosage of $20 \mathrm{~g} / \mathrm{L}$ with the highest $\mathrm{OE}$ (oxidant efficiency) value was economically suitable for chlorinated organic solvents removal. The increasing temperature contributed to the increasing depletion of chlorinated organic solvents. Chlorinated ethenes were more easily removed than chlorinated ethanes. Moreover, the persulfate depletion followed the pseudo-first-order reaction kinetics $\left(k_{p s}=0.0292[\mathrm{PS}]_{0}+\right.$ $\left.0.0008, R^{2}=0.9771\right)$. Heat-activated persulfate appeared to be an effective oxidant for treatment of chlorinated hydrocarbons.
\end{abstract}

\section{Introduction}

The chlorinated organic solvents such as trichloroethene (TCE), cis-1,2-dichloroethene (cis-1,2-DCE), 1,1,1-trichloroethane (TCA), and 1,2-dichloroethane (1,2-DCA) have been widely used for decades as a degreasing agent, a cleaning agent, and organic synthesis intermediates in chemical, pharmaceutical, electronic, tanning, printing, and other industries [1-3]. The chlorinated organic solvents were considered as priority toxic pollutants and associated risks to humans representing a public health threat. Historically, the improper disposal of these chlorinated organic solvents has resulted in extensive contamination of soils and groundwater. Due to the high density and low water solubility, the chlorinated organic solvents sink beneath the water table, do not pool, and rather continue to migrate downward in the aquifer, displacing the water until reaching a formation of sufficient impermeability to prevent further migration. That is, it will last a long time, once subsurface medium was contaminated. Therefore, it is urgent to find a fast and efficient method to remediate chlorinated solvents in soils.

In situ chemical oxidation (ISCO) is a remediation technology used to clean up contaminated soils and groundwater in-place. It has been greatly recognized and widely applied in many contaminated field sites. The typical oxidants used for ISCO are potassium permanganate, hydrogen peroxide (Fenton's reagent), and ozone [4]. Each oxidant has its limitations (e.g., persistence, reactivity, etc.) within a soil matrix [5]. Recently, persulfate $\left(\mathrm{Na}_{2} \mathrm{~S}_{2} \mathrm{O}_{8}, \mathrm{PS}\right)$ emerged as an efficient oxidant for ISCO applications with the properties of high water solubility, no odor, effectiveness of oxidation over a wide range of $\mathrm{pH}$, and lower affinity for soil organics [6]. The use of persulfate for soil and groundwater treatment holds a lot of promise as persulfate can combine the strength of hydrogen peroxide with the stability of permanganate [4]. Persulfate can be thermally [2, 7-9], chemically [10-12], or photochemically [13] activated to generate the powerful oxidant known as the sulfate free radical $\left(\mathrm{SO}_{4}{ }^{-} \cdot\right)$, with a redox potential of $2.6 \mathrm{~V}$ [14], which can be instrumental in the destruction of most organic contaminants commonly present in soil and groundwater including trichloroethylene $[5,6,15]$, naphthalene [11], and phenol $[8,13,16]$. Compared with other activations, heat activation is the most effective activation technology. Thermally activated persulfate oxidation of chlorinated organic solvents such as TCE has been quite successful in remediating groundwater contaminant. 


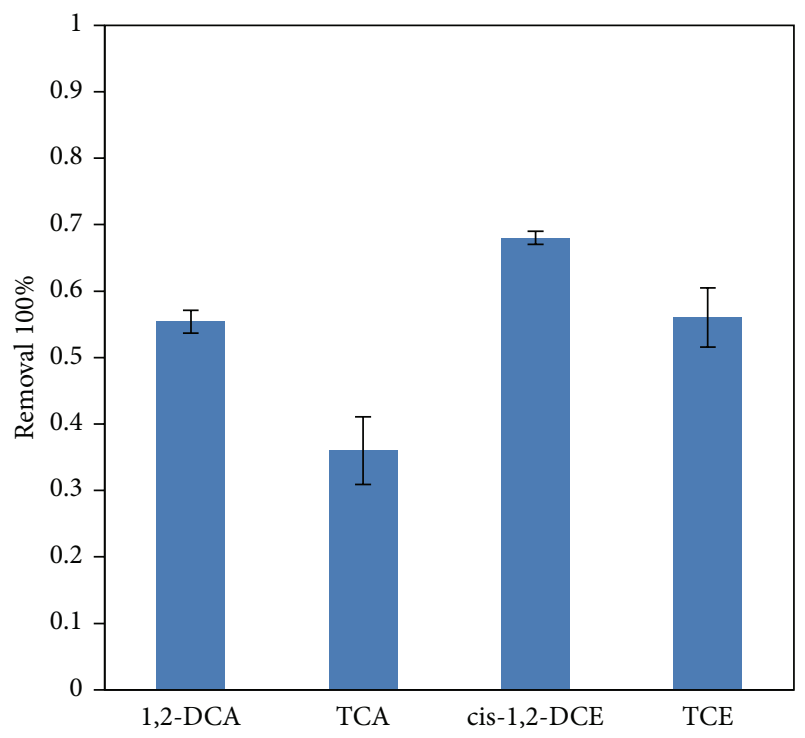

(a)



(c)

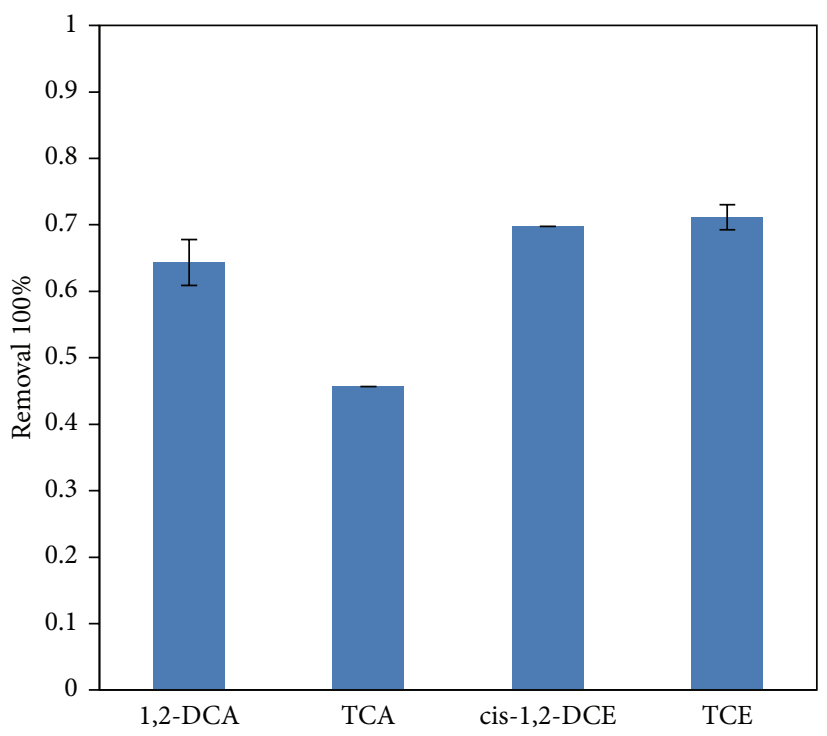

(b)

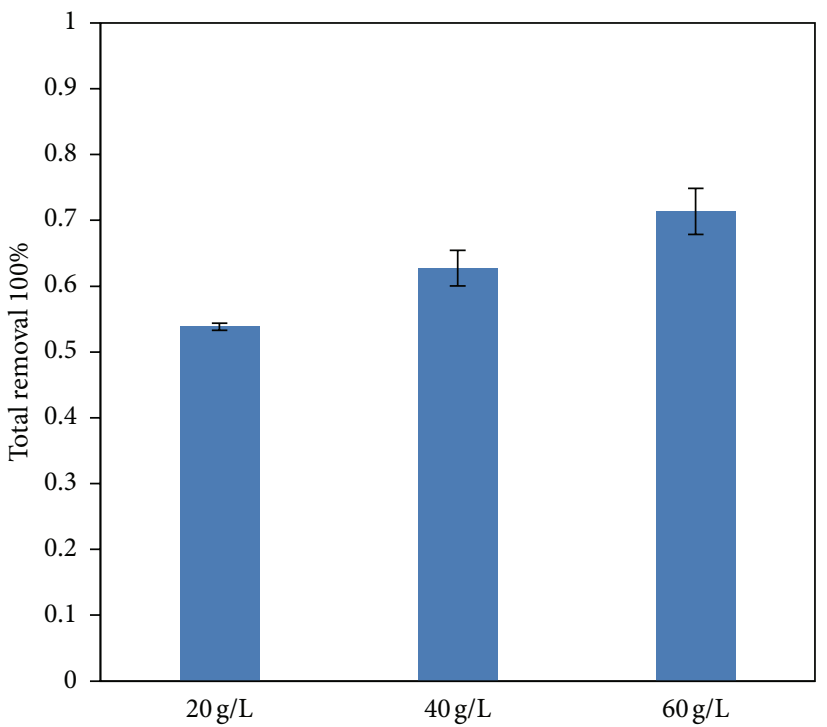

(d)

Figure 1: The depletion of chlorinated organic solvents by activated persulfate at $30^{\circ} \mathrm{C}$ with different persulfate dosages: (a) $20 \mathrm{~g} / \mathrm{L},(\mathrm{b}) 40 \mathrm{~g} / \mathrm{L}$, and (c) $60 \mathrm{~g} / \mathrm{L}$, and (d) the total removal of chlorinated organic solvents.

However, most studies focus on the treatment of single contaminants, such as TCE or TCA, and focus on the treatment of groundwater rather than soils.

In this study, research focuses on the heat-activated persulfate oxidative treatment of organic compounds containing chlorinated ethenes and ethanes in the subsurface medium. The most suitable persulfate dosage for chlorinated organic compounds depletion was determined and the influence of activated persulfate oxidative chlorinated organic compounds under different temperature was investigated.

\section{Materials and Methods}

2.1. Materials. All chemicals were of analytical grade except for methanol $\left(\mathrm{CH}_{3} \mathrm{OH},>99.5 \%\right.$, Sinopharm Chemical Reagent Co., Ltd.) which was of HPLC grade. Persulfate $\left(\mathrm{Na}_{2} \mathrm{~S}_{2} \mathrm{O}_{8},>98.0 \%\right)$ was purchased from Sinopharm Chemical Reagent Co., Ltd, and used as oxidizer. The pure trichloroethene (TCE, >99.0), cis-1,2-dichloroethene (cis-1,2DCE, >99.0\%), 1,1,1-trichloroethane (TCA, >94.0\%), and 1,2-dichloroethane (1,2-DCA, >99.0\%) were purchased from 
Sinopharm Chemical Reagent Co., Ltd, and diluted to the certain concentration for each experiment. Methanol was used to extract the organic contaminants from soil slurry samples and to quench the oxidation reaction. Sodium bicarbonate $\left(\mathrm{NaHCO}_{3},>99.0 \%\right)$ and potassium iodide (KI, >99.0\%) were purchased from Sinopharm Chemical Reagent Co., Ltd, and used for persulfate analysis. Mixed standard solutions $(10 \mu \mathrm{g} / \mathrm{mL})$ of trichloroethene (TCE), cis-1,2-dichloroethene (cis-1,2-DCE), 1,1,1-trichloroethane (TCA), and 1,2-dichloroethane (1,2-DCA) in purge and trap grade methanol were purchased from Sinopharm Chemical Reagent Co., Ltd, and used as an internal standard for gas chromatography analysis. Ultrapure water from a Millipore system was used in the experiments.

Coarse sandy soil $(0.5-2 \mathrm{~mm})$ was prepared.

2.2. Laboratory Experiments. The mixed solution of TCE, cis1,2-DCE, TCA, and 1,2-DCA was prepared as stock solution and diluted to the certain concentration $(81.8,71.2,75.0$, and $70.6 \mathrm{mg} / \mathrm{L}$ of TCE, cis-1,2-DCE, TCA, and 1,2-DCA, resp.) for each experiment. And a series of $30 \mathrm{~mL}$ brown reaction bottles equipped with Agilent caps and TFE liners were used for all tests. For each test, $25 \mathrm{~mL}$ water and $25 \mathrm{~g}$ soil were sequentially added to the reaction bottle with the solid-water ratio of $1: 1$ and mixed followed by injection of $7 \mu \mathrm{L}$ mixed contaminated solution and a predetermined amount of persulfate solution. Finally, a predetermined amount of water was added via a syringe to make sure the reaction bottle filled with no air bubbles. All the reaction bottles were shaken continuously on a ZWY-240 thermostatic reciprocating shaker at $100 \mathrm{r} / \mathrm{min}$. At each time interval, $50 \mu \mathrm{L}$ sample was collected via a syringe from each reaction bottle for persulfate analysis and $50 \mu \mathrm{L}$ sample was collected with methanol addition for organic compounds analysis. All experiments were conducted in duplicate. Control tests in the absence of persulfate were also carried out.

2.3. Analysis. Persulfate anion concentration was determined using a spectrophotometric method with potassium iodide [17]. The organic compounds (TCE, DCE, TCA, and DCA) were quantified using HP7890A gas chromatography equipped with a column HP-5MS $(30 \mathrm{~m} \times 0.25 \mathrm{~mm} \times$ $0.25 \mu \mathrm{m}$ ) capillary column.

\section{Results and Discussion}

3.1. Influence of Persulfate Dosage. The depletion of chlorinated organic solvents by activated persulfate at $30^{\circ} \mathrm{C}$ was illustrated in Figure 1. The low TCA removal was obtained at the persulfate concentration of 20,40 , or $60 \mathrm{~g} / \mathrm{L}$. The high removal was up to $79.5 \%, 74.0 \%, 69.7 \%$, and $54.8 \%$ of TCE, cis-1,2-DCE, 1,2-DCA, and TCA, respectively, while the persulfate concentration of $60 \mathrm{~g} / \mathrm{L}$ was carried out. The phenomenon showed that chlorinated ethenes (TCE and cis-1,2-DCE) were more easily removed than chlorinated ethanes (TCA and 1,2-DCA). Chlorinated organic solvents removal was increased as persulfate concentration increased (shown in Figure 1(d)), but meanwhile, more persulfate could



Figure 2: The decomposition of persulfate in the reactive system.

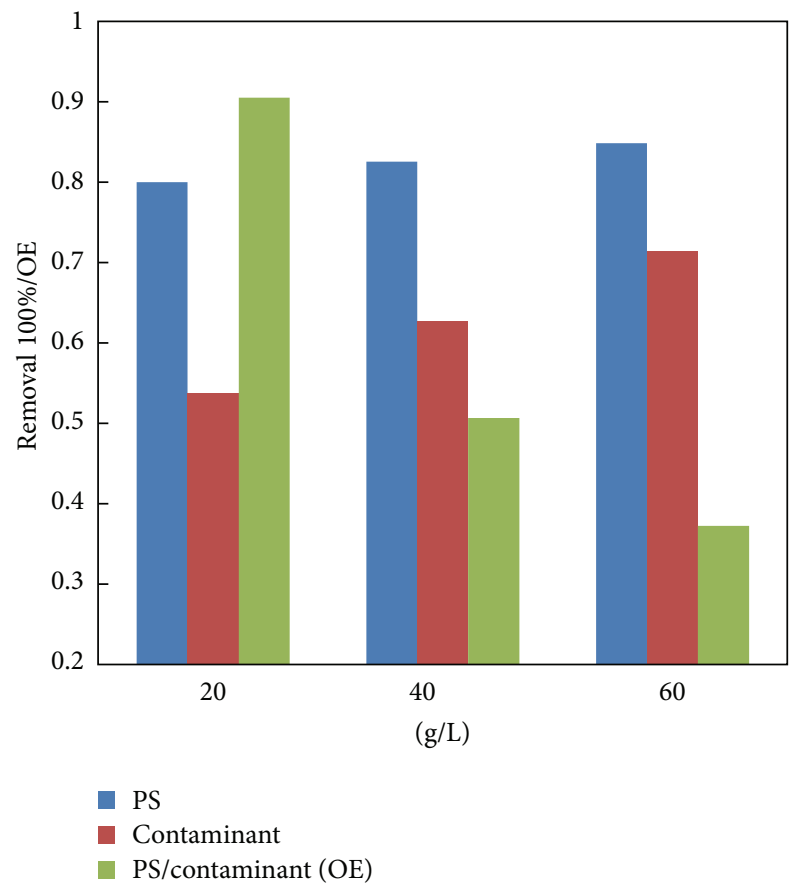

FIgURE 3: The decomposition of persulfate and contaminants after $72 \mathrm{~h}$ reaction time and the oxidant efficiency in the reactive system.

be decomposed (shown in Figure 2). The semilogarithmic graphs of $[\mathrm{PS}] /[\mathrm{PS}]_{0}$ under different initial persulfate concentration as a function of reaction time were shown in Figure 2. Results demonstrated that the depletion rate was pseudofirst-order with respect to the initial persulfate concentration, and a similar result was described by Deng et al. [9]. For a given $[\mathrm{PS}]_{0}$, the depletion rate constant $k_{p s}$ decreased from 0.0035 to $0.0084 \mathrm{~h}^{-1}$ with increasing initial persulfate concentration $\left([\mathrm{PS}]_{0}\right.$ ) from 20 to $60 \mathrm{~g} / \mathrm{L}$. As shown in the 


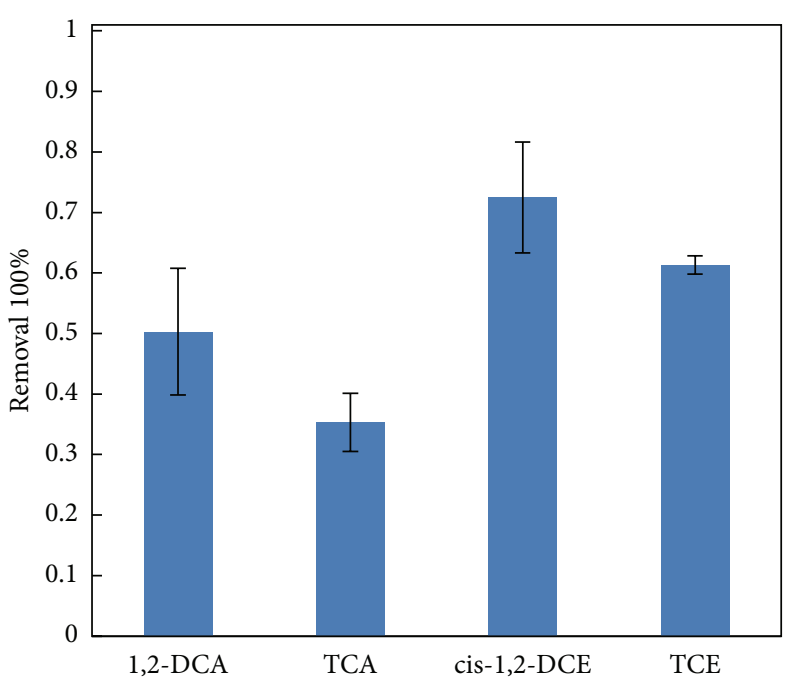

(a)

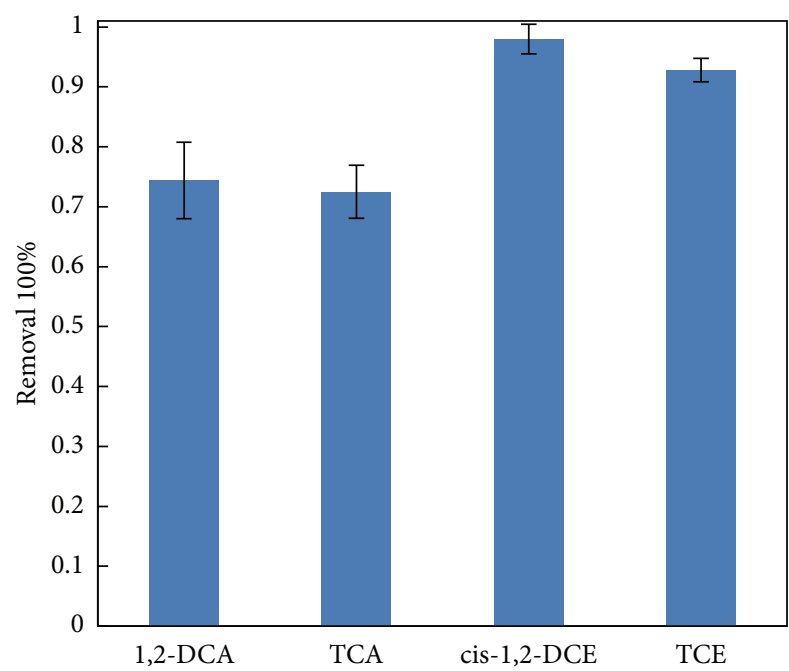

(c)

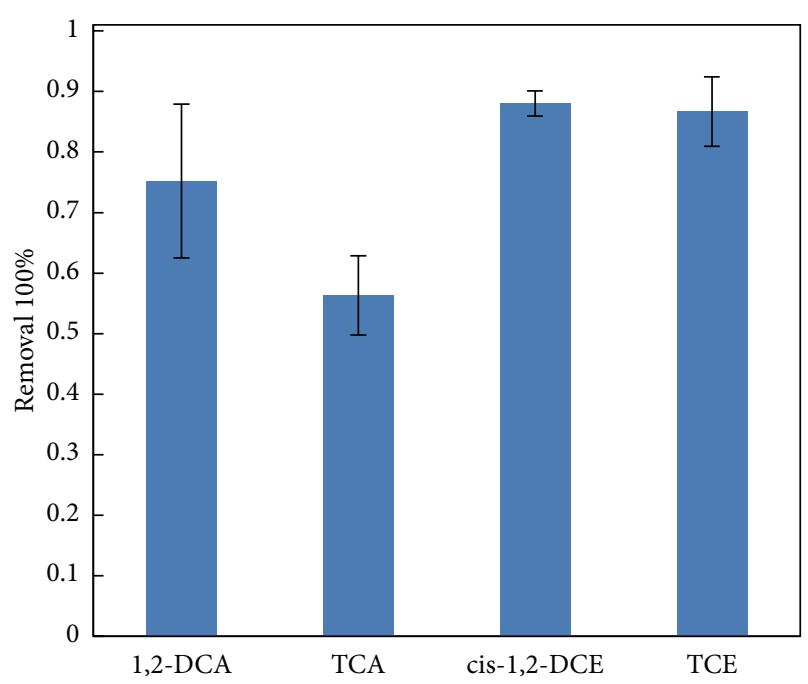

(b)

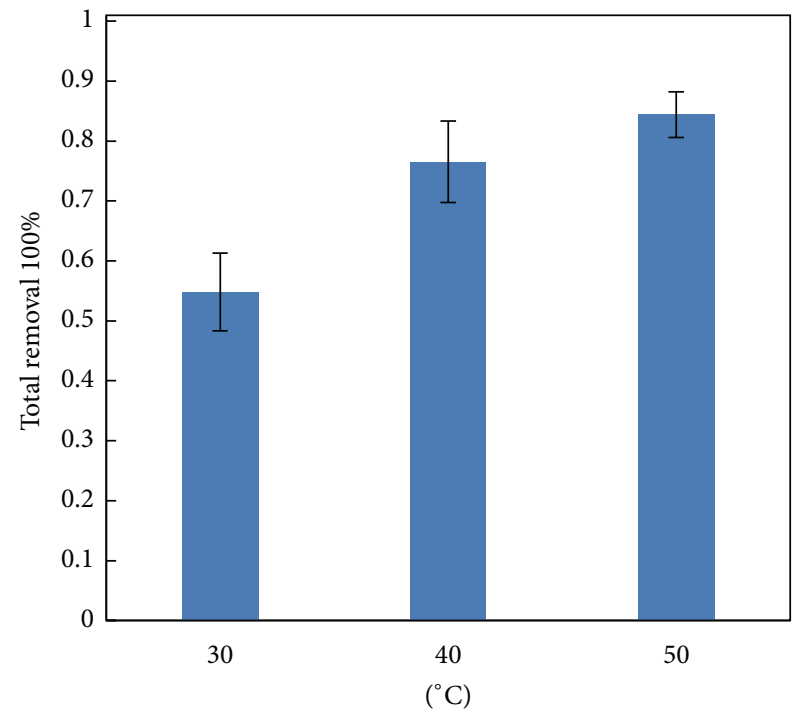

(d)

FIGURE 4: The depletion of chlorinated organic solvents by activated persulfate at different temperatures: (a) $30^{\circ} \mathrm{C}$, (b) $40^{\circ} \mathrm{C}$, and (c) $50^{\circ} \mathrm{C}$ after $72 \mathrm{~h}$ reaction time.

insert image of Figure 2, the depletion rate constant exhibits a linear trend $\left(k_{p s}=0.0292[\mathrm{PS}]_{0}+0.0008, R^{2}=0.9771\right)$. Therefore, the test with increasing persulfate dosage resulted in more decomposed persulfate. Moreover, the test with $20 \mathrm{~g} / \mathrm{L}$ persulfate concentration resulted in the highest $\mathrm{OE}$ value (the oxidant efficiency ( $\mathrm{mmol}$ of contaminant depletion per g of persulfate decomposition)) [18], shown in Figure 3. Thus, the persulfate dosage of $20 \mathrm{~g} / \mathrm{L}$ was economically suitable for chlorinated organic solvents removal.

3.2. Influence of Temperature. The depletion of chlorinated solvents by thermal activated persulfate at different temperatures was illustrated in Figure 4. Results showed that cis-1,2DCE obtained the highest removal by activated persulfate, followed by TCE, 1,2-DCA, and TCA at $30^{\circ} \mathrm{C}, 40^{\circ} \mathrm{C}$, or $50^{\circ} \mathrm{C}$.
The test with $30^{\circ} \mathrm{C}$ resulted in the low 1,2-DCA, TCA, cis-1,2DCE, and TCE removal of 50.3\%, 35.3\%, $72.5 \%$, and $61.3 \%$, respectively. Compared with TCA and TCE, 1,2-DCA and cis1,2-DCE obtained higher removal which related to the active molecular structure. The highest TCE, cis-1,2-DCE, 1,2-DCA, and TCA removal was up to $79.5 \%, 74.0 \%, 69.7 \%$, and $54.8 \%$, respectively, while the test with temperature $50^{\circ} \mathrm{C}$ was carried out. In general, the depletion of chlorinated solvents was increased with increasing temperature. First, the increasing temperature resulted in higher activation energy, which is in favor of generating the significant oxidant $\left(\mathrm{SO}_{4}{ }^{-} \bullet\right)$. Second, the high temperature can accelerate the reaction of chlorinated organic solvents with persulfate. Moreover, heat can also accelerate desorption from soil phase to aqueous phase, which contributes to the further destruction of chlorinated organic solvents. 


\section{Conclusion}

In this study, heat-activated persulfate appeared to be the most effective oxidant for treatment of chlorinated organic solvents. Chlorinated organic solvents removal was increased as persulfate concentration increased. The persulfate dosage of $20 \mathrm{~g} / \mathrm{L}$ with the highest $\mathrm{OE}$ (oxidant efficiency) value was economically suitable for chlorinated organic solvents removal. The increasing temperature contributed to the increasing depletion of chlorinated organic solvents. Chlorinated ethenes (TCE and cis-1,2-DCE) were more easily removed than chlorinated ethanes (TCA and 1,2-DCA). Moreover, the persulfate depletion followed the pseudo-firstorder reaction kinetics $\left(k_{p s}=0.0292[\mathrm{PS}]_{0}+0.0008, R^{2}=\right.$ 0.9771).

\section{Conflict of Interests}

The authors declare that there is no conflict of interests regarding the publication of this paper.

\section{Acknowledgment}

The present work was funded by National Natural Science Foundation of China (Grant no. 41302182).

\section{References}

[1] K. R. Weeks, C. J. Bruell, and N. R. Mohanty, "Use of Fenton's reagent for the degradation of TCE in aqueous systems and soil slurries," Soil and Sediment Contamination, vol. 9, no. 4, pp. 331$345,2000$.

[2] X. G. Gu, S. G. Lu, L. Li et al., "Oxidation of 1,1,1-trichloroethane stimulated by thermally activated persulfate," Industrial and Engineering Chemistry Research, vol. 50, no. 19, pp. 11029-11036, 2011.

[3] X. Gu, S. Lu, Z. Qiu et al., "Comparison of photodegradation performance of 1,1,1-trichloroethane in aqueous solution with the Addition of $\mathrm{H}_{2} \mathrm{O}_{2}$ or $\mathrm{S}_{2} \mathrm{O}_{8}^{2-}$ oxidants," Industrial and Engineering Chemistry Research, vol. 51, no. 21, pp. 7196-7204, 2012.

[4] A. Tsitonaki, B. Petri, M. Crimi, H. Mosbk, R. L. Siegrist, and P. L. Bjerg, "In situ chemical oxidation of contaminated soil and groundwater using persulfate: a review," Critical Reviews in Environmental Science and Technology, vol. 40, no. 1, pp. 55-91, 2010.

[5] C. Liang, Z.-S. Wang, and C. J. Bruell, "Influence of $\mathrm{pH}$ on persulfate oxidation of TCE at ambient temperatures," Chemosphere, vol. 66, no. 1, pp. 106-113, 2007.

[6] C. Liang, Z.-S. Wang, and N. Mohanty, "Influences of carbonate and chloride ions on persulfate oxidation of trichloroethylene at $20^{\circ}$ C," Science of the Total Environment, vol. 370, no. 2-3, pp. 271-277, 2006.

[7] S. Bougie and J.-S. Dubé, "Oxidation of the isomers of dichlorobenzene with the aid of thermally activated sodium persulfate," Journal of Environmental Engineering and Science, vol. 6, no. 4, pp. 397-407, 2007.

[8] V. C. Mora, J. A. Rosso, D. O. Mártire, and M. C. Gonzalez, "Phenol depletion by thermally activated peroxydisulfate at 70॰C," Chemosphere, vol. 84, no. 9, pp. 1270-1275, 2011.
[9] J. Deng, Y. Shao, N. Gao, Y. Deng, S. Zhou, and X. Hu, "Thermally activated persulfate (TAP) oxidation of antiepileptic drug carbamazepine in water," Chemical Engineering Journal, vol. 228, pp. 765-771, 2013.

[10] G. P. Anipsitakis and D. D. Dionysiou, "Radical generation by the interaction of transition metals with common oxidants," Environmental Science and Technology, vol. 38, no. 13, pp. 37053712, 2004

[11] D. Y. S. Yan and I. M. C. Lo, "Removal effectiveness and mechanisms of naphthalene and heavy metals from artificially contaminated soil by iron chelate-activated persulfate," Environmental Pollution, vol. 178, pp. 15-22, 2013.

[12] Y. Leng, W. Guo, X. Shi et al., "Degradation of Rhodamine B by persulfate activated with $\mathrm{Fe}_{3} \mathrm{O}_{4}$ : effect of polyhydroquinone serving as an electron shuttle," Chemical Engineering Journal, vol. 240, pp. 338-343, 2014.

[13] Y.-T. Lin, C. Liang, and J.-H. Chen, "Feasibility study of ultraviolet activated persulfate oxidation of phenol," Chemosphere, vol. 82, no. 8, pp. 1168-1172, 2011.

[14] R. E. Huie, C. L. Clifton, and P. Neta, "Electron transfer reaction rates and equilibria of the carbonate and sulfate radical anions," International Journal of Radiation Applications and Instrumentation C: Radiation Physics and Chemistry, vol. 38, no. 5, pp. 477-481, 1991.

[15] K. Li, M. I. Stefan, and J. C. Crittenden, "Trichloroethene degradation by $\mathrm{UV} / \mathrm{H}_{2} \mathrm{O}_{2}$ advanced oxidation process: product study and kinetic modeling," Environmental Science \& Technology, vol. 41, no. 5, pp. 1696-1703, 2007.

[16] C. Liang and H.-W. Su, "Identification of sulfate and hydroxyl radicals in thermally activated persulfate," Industrial \& Engineering Chemistry Research, vol. 48, no. 11, pp. 5558-5562, 2009.

[17] C. Liang, C.-F. Huang, N. Mohanty, and R. M. Kurakalva, "A rapid spectrophotometric determination of persulfate anion in ISCO," Chemosphere, vol. 73, no. 9, pp. 1540-1543, 2008.

[18] L. R. Bennedsen, J. Muff, and E. G. Søgaard, "Influence of chloride and carbonates on the reactivity of activated persulfate," Chemosphere, vol. 86, no. 11, pp. 1092-1097, 2012. 



\section{Carbohydrate} Chemistry



The Scientific World Journal
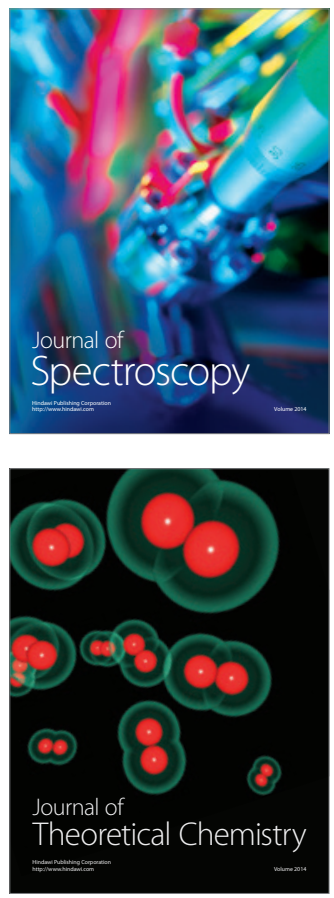


Submit your manuscripts at

http://www.hindawi.com

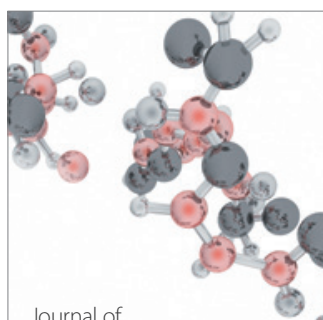

Analytical Methods

in Chemistry

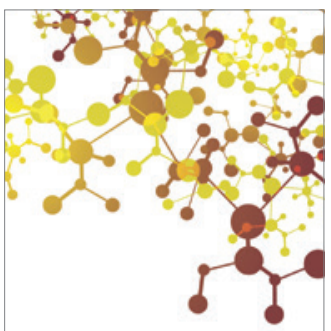

Journal of

Applied Chemistry

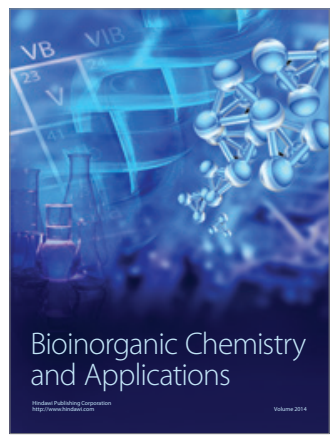

Inorganic Chemistry
